\title{
Removal of direct dyes by coagulation: The performance of preformed polymeric aluminum species
}

\author{
Baoyou Shi ${ }^{\mathrm{a}, *}$, Guohong $\mathrm{Li}^{\mathrm{b}}$, Dongsheng Wang ${ }^{\mathrm{a}}$, Chenghong Feng ${ }^{\mathrm{a}}$, Hongxiao Tang ${ }^{\mathrm{a}}$ \\ ${ }^{a}$ State Key Laboratory of Environmental Aquatic Chemistry, Research Center for Eco-Environmental Sciences, \\ Chinese Academy of Sciences, P.O. Box 2871, Beijing 100085, China \\ ${ }^{\mathrm{b}}$ School of Water Resources and Environment, China University of Geosciences, Beijing 100083, China
}

Received 2 May 2006; received in revised form 22 September 2006; accepted 25 September 2006

Available online 29 September 2006

\begin{abstract}
Removal of three direct dyes (Direct Black 19, Direct Red 28, and Direct Blue 86) by coagulation with three different Al based coagulants was investigated. The main purpose of this paper is to examine the coagulation features of polymeric aluminum coagulants in treatment of dye-polluted waters and the emphasis was placed on the roles of preformed $\mathrm{Al}$ species, particularly $\mathrm{Al}_{13}$. The performance of $\mathrm{Al}_{13}$ in coagulation of dyes was observed through jar tests by comparing traditional $\mathrm{Al}$ salt, polyaluminum chloride $(\mathrm{PACl})$, and purified $\mathrm{Al}_{13}$. The results showed that under most cases $\mathrm{Al}_{13}$ had significantly higher efficiency in removal of direct dyes than traditional $\mathrm{Al}$ salt and commercial PACl with the exception of Direct Red 28 removal under high $\mathrm{pH}$ range. The coagulation of direct dyes could be greatly affected by $\mathrm{pH}$. Reducing $\mathrm{pH}$ was favorable for preformed $\mathrm{Al}$ species in a broad $\mathrm{pH}$ range. For traditional $\mathrm{Al}$ coagulant, efficient dye removal only occurred in a relatively narrow $\mathrm{pH}$ range of near 6.0 . The outstanding coagulation behavior of $\mathrm{Al}_{13}$ could be ascribed to its high charge neutralization ability, relative stability and potential self-assembly tendency.
\end{abstract}

(C) 2006 Elsevier B.V. All rights reserved.

Keywords: Direct dye; Coagulation; $\mathrm{Al}$ speciation; Polyaluminum chloride; $\mathrm{Al}_{13}$

\section{Introduction}

The release of dye compounds from industries of textile dyeing, printing, as well as food and papermaking can cause severe water pollution problems. It has been estimated that more than 700,000 tonnes of dyestuff are produced annually, and about $10-15 \%$ of these dyes are left in effluents during dyeing processes $[1,2]$. The presence of dyes in water is aesthetically undesirable, even very low concentration of dyes is highly visible. On the other hand, dye polluted natural waters can result in serious disturbance to aquatic biosphere due to the reduction of sunlight penetration and depletion of dissolved oxygen. Additionally, the majority of synthetic dyes are highly water-soluble azo dyes, which are toxic to some aquatic organisms and may pose serious health threat to human beings. It has been found that some azo dyes are able to produce carcinogenic aromatic amines

\footnotetext{
* Corresponding author. Tel.: +86 1062849138 ; fax: +86 1062923541 . E-mail address: byshi@ rcees.ac.cn (B. Shi).
}

in the process of reductive degradation $[3,4]$. In the recent years, regulations on dye pollutants are becoming more and more stringent world widely. Thus, dyes in wastewater have to be removed completely before discharged into receiving waters.

However, since synthetic dye compounds usually have very complex structure and are intentionally designed to be recalcitrant with poor biodegradability, they are difficult to decolorize by conventional aerobic biological treatments, such as activated sludge process. The widely used methods for dyeing wastewater treatment involve many physical-chemical techniques, such as coagulation, adsorption, membrane filtration, and advanced oxidation, etc. [5-8]. Each treatment method has its advantages and disadvantages. Generally, advanced oxidation processes are effective for removal of most dyes, but a common problem with such operations is their relatively high cost in large-scale utilization [1,9]. In addition, chemical oxidation usually attacks only the chromophore groups of dyes instead of mineralizing organic dyes completely. Moreover, the possible occurrence of some more toxic intermediate products could be of concern. Adsorption techniques have much potential in the treatment of 
dye-containing waters if high performance and cheap adsorbents are available [10]. Membrane filtration has some special features unrivalled by other methods, but the high capital cost and clogging problems associated with this method may limit its application.

Coagulation/flocculation is one of the most popular unit operations in water and wastewater treatment trains. Dye removal by coagulation is not based on the partial decomposition of dye compounds, thus no potentially harmful and toxic intermediates are produced. Furthermore, this process can be used in large-scale operation with relatively high operability and cost effectiveness $[2,11,12]$. A limitation of this technique is that some high-soluble, low molecular and cationic dyes might not be effectively removed. The disposal of sludge produced by coagulation could be another restriction associated with this technique.

Although the application of coagulation in water and wastewater treatment has a long history, the mechanisms involved in this process are still not fully understood. Coagulation is a very complicated process involving a series of physical-chemical interactions. The type of coagulant applied can play important roles in the removal of target pollutants. Aluminum and ferric-based salts, such as alum, aluminum chloride, ferric chloride, ferric sulfate, are commonly used traditional coagulants. After dosing, aluminum and ferric ions will experience continuous self-hydrolysis and evolve into hydroxide solids finally. The in situ formed hydrolysis products and hydroxide solids can neutralize, and/or adsorb particulate and dissolved matters to achieve removal of pollutants. The hydrolyzing process of aluminum and ferric salts are subject to water quality conditions. Alkalinity, $\mathrm{pH}$, temperature and co-existing ions can significantly affect the treatment effectiveness of such traditional coagulants. During the last decades, inorganic polymer flocculants (IPFs) are receiving more and more attention as a new generation of flocculants. Polyaluminum chloride ( $\mathrm{PACl})$ is one of the most important IPFs and being more and more widely used in the world. $\mathrm{PACl}$ contains polymeric $\mathrm{Al}$ species formed by partially neutralization. The preformed $\mathrm{Al}$ species in $\mathrm{PACl}$ are relatively stable after dosing, and thus their effectiveness can be less influenced by the specific water quality conditions [13-17]. $\mathrm{Al}_{13}\left(\left[\mathrm{AlO}_{4} \mathrm{Al}_{12}(\mathrm{OH})_{24}\left(\mathrm{H}_{2} \mathrm{O}\right)_{12}\right]^{7+}\right)$ is considered as the most important species in $\mathrm{PACl}$ and has long been research interest.

The removal of reactive and disperse dyes by regular coagulation and electro-coagulation has been studied by some researchers [9,18-22]. The coagulants used in most of the studies are traditional aluminum, ferric-based salts or synthesized organic coagulants. Although $\mathrm{PACl}$ has ever been applied in color removal $[9,22]$, the comparative study on coagulation of dye by $\mathrm{PACl}$ and traditional $\mathrm{Al}$ salts has not been extensively and systematically carried out to date. Furthermore, the potential roles of $\mathrm{Al}_{13}$ in dye removal need to be elucidated.

In this work, the coagulation behaviors of direct dye removal by different Al based coagulants were investigated in detail using jar tests. Emphasis was placed on the distinct roles of $\mathrm{Al}_{13}$ species in coagulation of direct dyes. Three commonly used direct dyes were chosen as model dye pollutants. $\mathrm{AlCl}_{3}$ and commercially available $\mathrm{PACl}$ were applied as typical traditional coagulant and inorganic polymer flocculant. Since PACl contains multiple $\mathrm{Al}$ species including both $\mathrm{Al}_{13}$ and colloidal species, it is difficult to distinguish the roles of $\mathrm{Al}_{13}$ from other species. In this study, laboratory purified $\mathrm{Al}_{13}$ as a novel material was utilized to identify the exclusive functions of $\mathrm{Al}_{13}$. The effect of $\mathrm{pH}$ on coagulation was examined to give better insights into the possible mechanisms involved in direct dye removal by different Al species.

\section{Experimental}

\subsection{Dye compounds and test waters}

Three direct dyes-Direct Black 19, Direct Red 28, and Direct Blue 86 (Tianjin Chemical Material Co., China) were used to simulate dye-polluted waters. These dyes were selected because they are currently among the widely used commercial dyes, especially in some Asian countries. In addition, the chemical structures of these dyes are different so that the treatability of dyes with different molecular characteristics could be compared. The molecular structures of these dye compounds are presented in Fig. 1. Stock dye solutions of $1000 \mathrm{mg} \mathrm{l}^{-1}$ were prepared and then diluted using tap water to obtain final concentration of $50 \mathrm{mg} \mathrm{l}^{-1}$. The $\mathrm{pH}$ of the simulated test water was controlled within $7.80 \pm 0.05$; the alkalinity was $155 \mathrm{mg} \mathrm{l}^{-1}$ as $\mathrm{CaCO}_{3}$. The wavelengths of maximum absorbance $\left(\lambda_{\max }\right)$ of these dyes with the background of tap water were determined according to scanning patterns performed on an UV-vis 8500 Spectrophotometer (Shanghai, China). The $\lambda_{\max }$ values of Direct Black 19, Direct Red 28 and Direct Blue 86 in the visible light range are shown in Table 1.

\subsection{Coagulants and speciation characterization}

Analytical grade of $\mathrm{AlCl}_{3} \cdot 6 \mathrm{H}_{2} \mathrm{O}$ was used as traditional $\mathrm{Al}$ salt. Solid PACl product was obtained from Wanshui ${ }^{\circledR}$ Water Purifying Chemicals Co. (Beijing, China). Purified $\mathrm{Al}_{13}$ material was prepared in laboratory following the method described in [23]. The coagulants were dissolved in deionized water, and the total Al concentrations were measured using ICP-OES (1100$1155 \mathrm{~V}$, Jarrell-Ash, USA). The species distribution of these coagulants was characterized by both ferron assay [24] and ${ }^{27} \mathrm{Al}$ NMR (Avance 500, Bruker, USA). Ferron assay can differentiate $\mathrm{Al}$ species into three categories: $\mathrm{Al}_{\mathrm{a}}$, the monomeric species; $\mathrm{Al}_{\mathrm{b}}$, the polymeric species; $\mathrm{Al}_{\mathrm{c}}$, the colloidal species. ${ }^{27} \mathrm{Al}$ NMR technique can identify both monomeric and $\mathrm{Al}_{13}$ species. The ${ }^{27} \mathrm{Al}$ NMR patterns of the three coagulants are demonstrated in Fig. 2. The signal at $0 \mathrm{ppm}$ corresponds to monomeric species

Table 1

The relationship between dye concentration $\left(C, \mathrm{mg} \mathrm{l}^{-1}\right)$ and absorbance $(A)$

\begin{tabular}{llll}
\hline Dye name & $\lambda_{\max }(\mathrm{nm})$ & Equation & $R^{2}$ \\
\hline Direct Black 19 & 630 & $C=144.9 A-0.1$ & 0.999 \\
Direct Red 28 & 490 & $C=117.6 A-0.4$ & 0.999 \\
Direct Blue 86 & 610 & $C=147.0 A+0.0$ & 0.998 \\
\hline
\end{tabular}


<smiles>Nc1ccc(N=Nc2ccc(N=Nc3c(N)c(O)c(N=Nc4ccc(N=Nc5ccc(N)cc5N)cc4)c4ccc([N+](=O)[O-])cc34)cc2)c(N)c1</smiles>

(a)

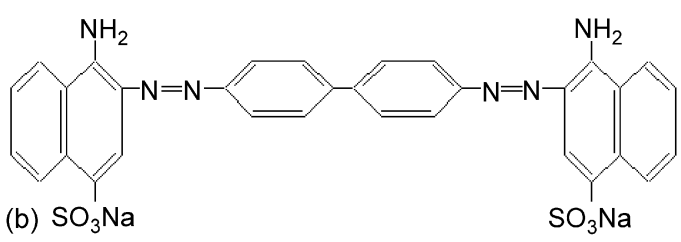

(c)

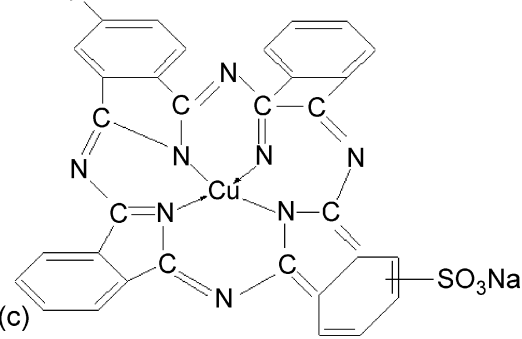

Fig. 1. Chemical structures of dye compounds (a) Direct Black 19, (b) Direct Red 28 and (c) Direct Blue 86.

and the signal at $62.5 \mathrm{ppm}$ corresponds to $\mathrm{Al}_{13}$ species (only the central $\mathrm{Al}$ atom in $\mathrm{Al}_{13}$ structure could produce resonance signal), the signal at $80 \mathrm{ppm}$ is ascribed to the inner standard of $\mathrm{NaAl}(\mathrm{OD})_{4}$. Other $\mathrm{Al}$ species, such as colloidal species could
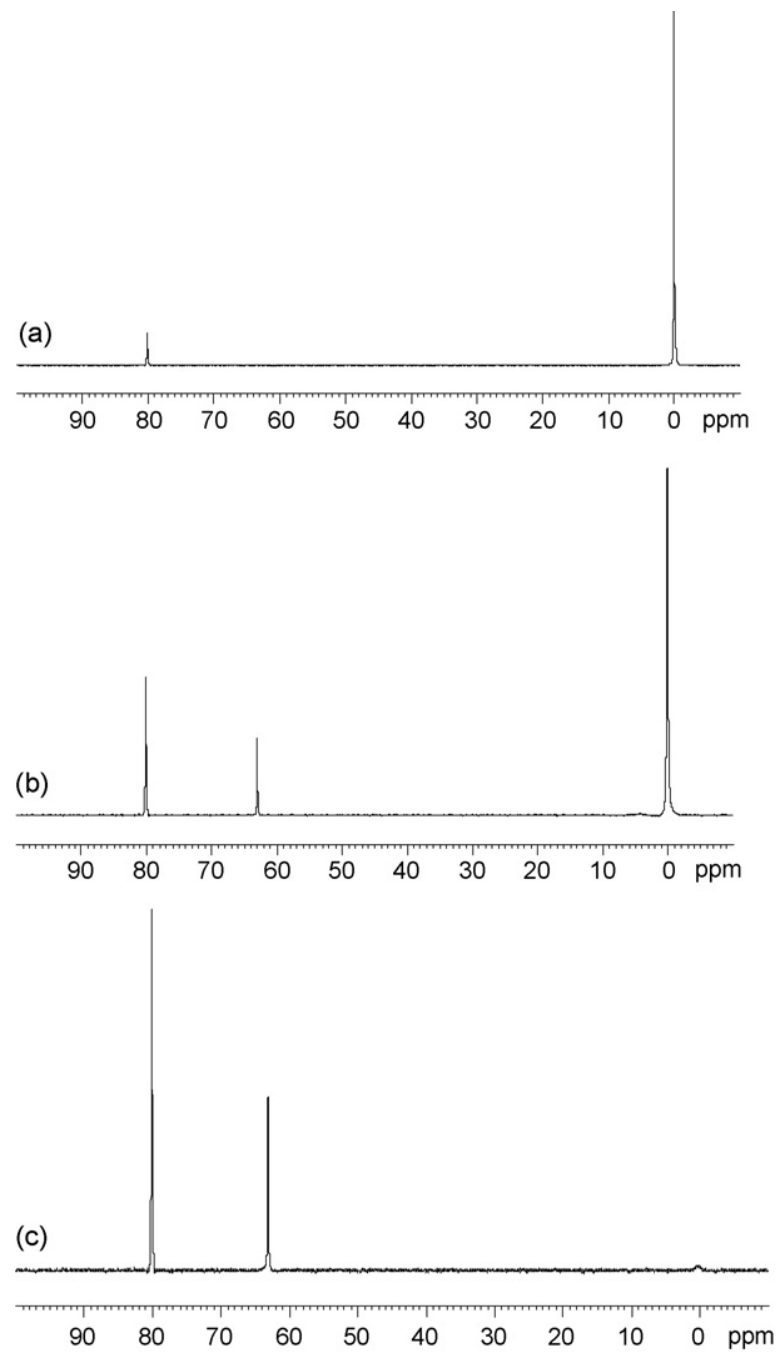

Fig. 2. ${ }^{27} \mathrm{Al}$ NMR patterns of coagulant solutions (a) $\mathrm{AlCl}_{3}$, (b) $\mathrm{PACl}$ and (c) $\mathrm{Al}_{13}$. not be observed by ${ }^{27} \mathrm{Al}$ NMR. Obviously, no $\mathrm{Al}_{13}$ was detected from $\mathrm{AlCl}_{3}$ solution, and both $\mathrm{Al}_{13}$ and monomeric $\mathrm{Al}$ species existed in $\mathrm{PACl}$. As to the purified $\mathrm{Al}_{13}$, the signal of monomeric species was almost negligible.

A current study found that the $\mathrm{Al}_{\mathrm{b}}$ species determined by ferron assay was equivalent to the $\mathrm{Al}_{13}$ species on the condition that the $\mathrm{B}$ value $(\mathrm{OH} / \mathrm{Al}$ molar ratio) was in the range of 1.5-2.5 [25]. In this work, the $\mathrm{B}$ values of the $\mathrm{PACl}$ and $\mathrm{Al}_{13}$ were 2.37 and 2.46 , respectively, thus the $\mathrm{Al}_{\mathrm{b}}$ component determined by ferron assay in both $\mathrm{PACl}$ and purified $\mathrm{Al}_{13}$ could be regarded as $\mathrm{Al}_{13}$ species. The speciation characteristics of three coagulants are listed in Table 2 . As evidenced by ${ }^{27} \mathrm{Al}$ NMR patterns, the predominant species of $\mathrm{AlCl}_{3}$ was $\mathrm{Al}$ monomers $\left(\mathrm{Al}_{\mathrm{a}}\right)$, accounted for $94.2 \%$; while, the $\mathrm{Al}_{\mathrm{b}}$ component $\left(\mathrm{Al}_{13}\right)$ of purified $\mathrm{Al}_{13}$ was as high as $95.8 \%$; $\mathrm{PACl}$ was consisted of mixed species with more than $50 \%$ of $\mathrm{Al}_{\mathrm{c}}$.

\subsection{Jar tests}

Jar tests were conducted on a program-controlled JTY-4 Jar Tester (Beijing, China). Dye containing test water of $500 \mathrm{ml}$ was transferred into a 800-ml beaker; under rapid stirring of $200 \mathrm{rpm}$, predetermined amount of coagulant was added, after $2 \mathrm{~min}$, the stirring was changed to $40 \mathrm{rpm}$ with a duration of $15 \mathrm{~min}$; then samples were collected and filtered using $0.45 \mu \mathrm{m}$ membrane filter for residual dye measurement. Turbidity was also measured (2100N Turbidimeter, Hach, USA) for some tests after $20 \mathrm{~min}$ of quiescent settling, samples for turbidity measurement were taken from $2 \mathrm{~cm}$ below the surface. The $\mathrm{pH}$ of test water was adjusted by adding $0.5 \mathrm{moll}^{-1}$ $\mathrm{HCl}$ and $0.1 \mathrm{moll}^{-1} \mathrm{NaOH}$ solutions. The measurement of

Table 2

Al species distribution of three different coagulants

\begin{tabular}{lllcrr}
\hline & $\begin{array}{l}\text { Concentration } \\
\left(\mathrm{mol} \mathrm{l}^{-1} \mathrm{Al}\right)\end{array}$ & $\mathrm{pH}$ & $\mathrm{Al}_{\mathrm{a}}(\%)$ & $\mathrm{Al}_{\mathrm{b}}(\%)$ & $\mathrm{Al}_{\mathrm{c}}(\%)$ \\
\hline $\mathrm{AlCl}_{3}$ & 0.20 & 2.62 & 94.2 & 5.8 & 0.0 \\
$\mathrm{PACl}$ & 0.20 & 3.65 & 17.6 & 29.9 & 52.5 \\
$\mathrm{Al}_{13}$ & 0.11 & 4.15 & 2.0 & 95.8 & 2.2 \\
\hline
\end{tabular}


pH was carried out using a MP220 pH meter (Mettler-Toledo, Switzerland).

\subsection{Measurement of residual dye concentration after coagulation}

The linear relationships between dye concentration and absorbance at wavelength of $\lambda_{\max }$ were obtained for each dye at $\mathrm{pH}$ of 7.80 (Table 1). For residual dye concentration measurement, the $\mathrm{pH}$ of filtered samples was adjusted to 7.80 first, and then the absorbance was read at wavelength of $\lambda_{\max }$. The residual dye concentration after coagulation was calculated based on the equations in Table 1. The removal was recorded as the ratio of residual dye concentration and initial test water concentration.

\section{Results and discussion}

\subsection{General coagulation behaviors of direct dyes}

Removal of Direct Black 19 by coagulation was firstly carried out under $\mathrm{pH}$ of 7.80 , which was the average $\mathrm{pH}$ value of tap water. The variations of dye removal with dosage are shown in Fig. 3 (the dosage was measured as " $\mathrm{mol} \mathrm{l}^{-1} \mathrm{Al}$ " in this paper). With the increase of coagulant dosage, the removal increased and the curves associated with different coagulants exhibited similar changing trends: slow increase at low dosages, then followed by a rapid increase with dosage; finally the increase became slow again and the curves approached plateau. The removal could be reached near $100 \%$ at high dosage zone for all three coagulants. Before reaching plateau, the coagulation efficiency was: $\mathrm{Al}_{13}>\mathrm{PACl}>\mathrm{AlCl}_{3}$. It should be pointed out that no re-stabilization phenomenon (removal reduction with increase of dosage) was observed even the dosage increased to $40 \times 10^{-5} \mathrm{moll}^{-1}$ (data are not included). The turbidity evolution with dosage is illustrated in Fig. 4. It was found that with the increase of dosage, the turbidity increased first and then decreased. Moreover, it was noticed that during the turbidity increasing phase, no observable flocs were formed. When the dosage was greater than a certain value (dosage corresponding

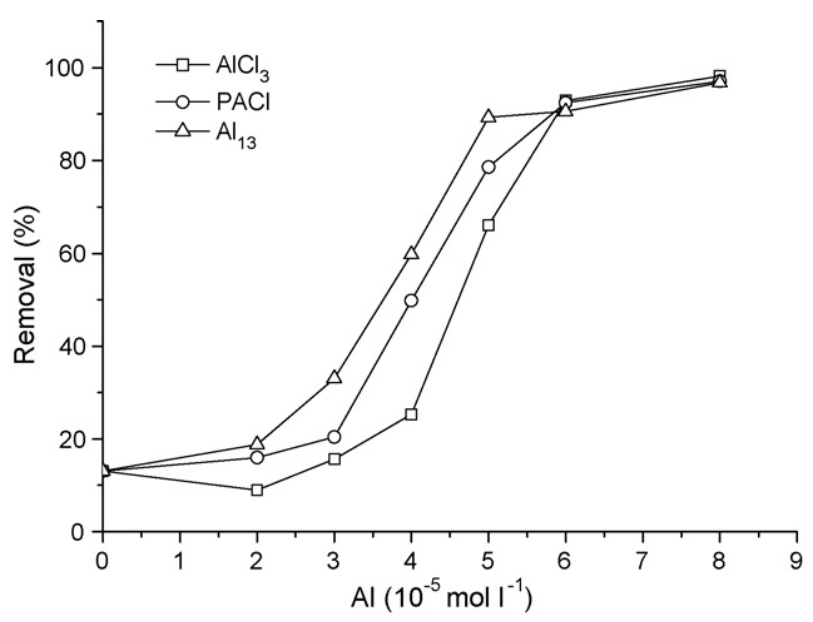

Fig. 3. Coagulation of Direct Black 19 under $\mathrm{pH}$ of 7.80

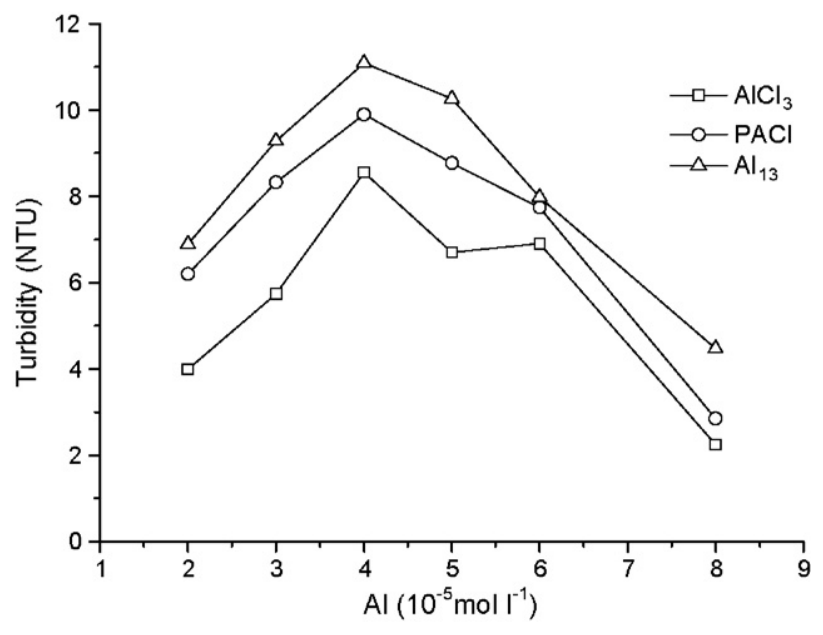

Fig. 4. Turbidity changes with dosage for coagulation of Direct Black 19.

to the maximum turbidity in Fig. 4), turbidity began to decrease and fine particulate matters could be seen with the increase of dosage. When the dosage was high enough, large flocs appeared. Fig. 4 also shows that during the turbidity increasing phase, coagulants related to higher dye removal also caused higher turbidity $\left(\mathrm{Al}_{13}>\mathrm{PACl}>\mathrm{AlCl}_{3}\right)$; in the turbidity decreasing phase, the dye removal efficiencies were all much high, but the settling velocity of flocs formed by $\mathrm{AlCl}_{3}$ was more rapid.

The coagulation of Direct Red 28 and Direct Blue 86 was examined under the same condition as that of Direct Black 19. Like the coagulation of Direct Black 19, it was also found that with the increase of dosage, turbidity increased first and then decreased with the appearance of appreciable particulates. However, the dye removal kept increase within the whole dosage range (Fig. 5). The dye removal performance of three coagulants exhibited different characteristics depending on the type of dyes and dosage levels. In the coagulation of Direct $\operatorname{Red} 28, \mathrm{Al}_{13}$ was
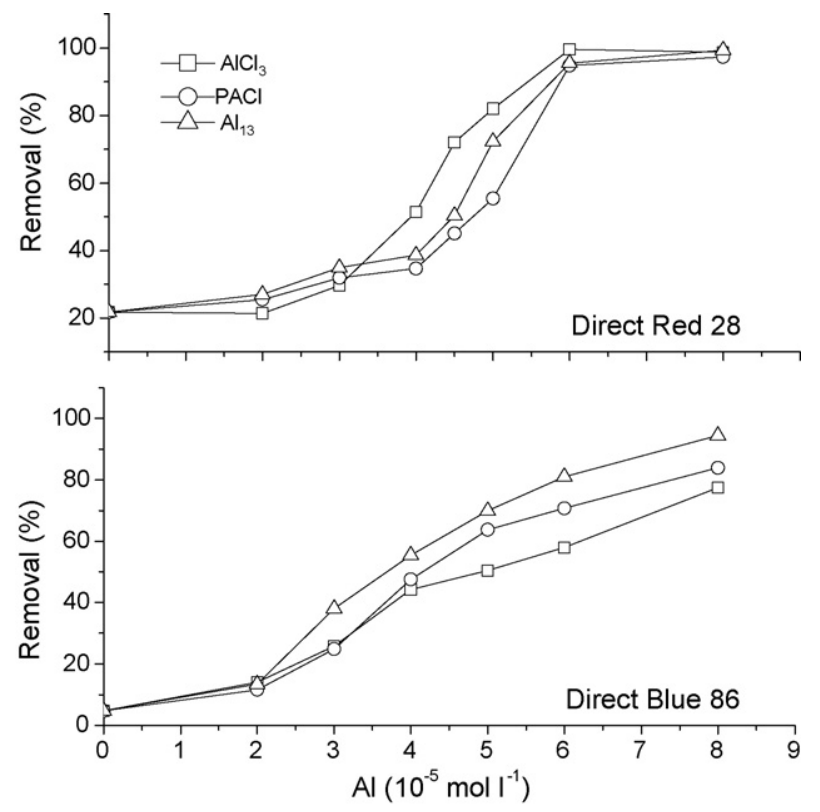

Fig. 5. Coagulation of Direct Red 28 and Direct Blue 86 under pH of 7.80. 
slightly superior to the other two coagulants when the dosage was low. With the increase of dosage, $\mathrm{AlCl}_{3}$ became the most efficient one. At the high dosage zone, the differences among three coagulants tended to diminish. While in the case of Direct Blue 86, $\mathrm{Al}_{13}$ achieved the highest removal within the whole dosage range, and $\mathrm{AlCl}_{3}$ was the poorest coagulant. It can also be observed that higher dosages were required for removal of Direct Blue 86 than for removal of other two dyes. At the dosage of $6 \times 10^{-5} \mathrm{moll}^{-1}$, the removal of Direct Red 28 had reached more than $90 \%$ for all coagulants, but the removal of Direct Blue 86 was only about 60,70 and $80 \%$ for $\mathrm{AlCl}_{3}, \mathrm{PACl}$ and $\mathrm{Al}_{13}$, respectively. It indicates that Direct Blue 86 was more difficult to be removed than the other two dyes. This phenomenon implies that the treatability of different dyes by coagulation might be associated with the properties of dyes themselves, such as molecular size and chemical structure. According to Fig. 1, the molecular sizes of both Direct Black 19 and Direct Red 28 are larger than Direct Blue 86 in at least one dimension (the longest dimension of Direct Black 19 molecule had been estimated to be $3 \mathrm{~nm}$ [10]). It is well recognized that organic matters with longer molecular chain and larger molecular weight are more favorable for removal by coagulation.

Fig. 6 demonstrates the $\mathrm{pH}$ changes after coagulation of Direct Blue 86: $\mathrm{pH}$ decreased with the increase of coagulant dosage. Once $\mathrm{AlCl}_{3}$ was dosed, the $\mathrm{pH}$ was depressed obviously. However, when the $\mathrm{PACl}$ and $\mathrm{Al}_{13}$ were dosed, only slight $\mathrm{pH}$ decrease could be observed. It can be explained by the differences of hydrolyzing potentials between monomeric and preformed polymeric $\mathrm{Al}$ species. $\mathrm{AlCl}_{3}$, mainly consisted of monomeric $\mathrm{Al}$ species, has much stronger hydrolyzing tendency than preformed polymeric coagulants once added into test
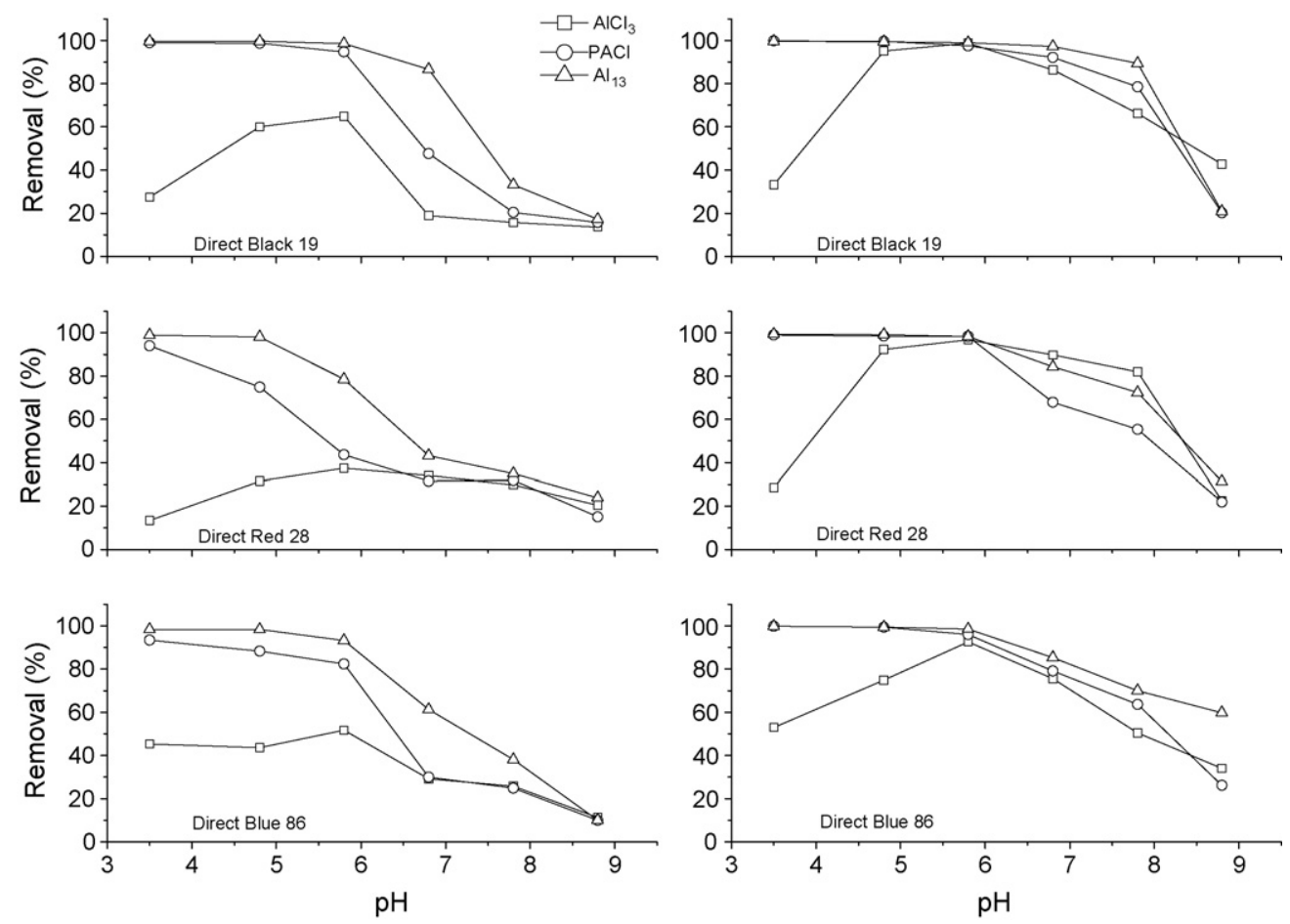

Fig. 7. Effect of $\mathrm{pH}$ on the removal of direct dyes by $\mathrm{AlCl}_{3}$, $\mathrm{PACl}$ and $\mathrm{Al}_{13}$ (left column: $\mathrm{Al}$ dosage of $3.0 \times 10^{-5}$ moll ${ }^{-1}$; right column: $\mathrm{Al}$ dosage of $\left.5.0 \times 10^{-5} \mathrm{moll}^{-1}\right)$. 
ducted under two dosage levels of low and medium: 3.0 and $5.0 \times 10^{-5} \mathrm{moll}^{-1}$, respectively. An obvious feature can be seen from the plots of Fig. 7 that the coagulation efficiencies of both $\mathrm{PACl}$ and $\mathrm{Al}_{13}$ tended to increase with the decrease of $\mathrm{pH}$ and approached almost complete dye removal when the $\mathrm{pH}$ was sufficiently low (less than 6.0). At the same time, appreciable and even large flocs were developed rapidly under depressed $\mathrm{pH}$ levels. However, the removal curves associated with different conditions were more or less different depending on the type of dyes, type of coagulants and level of dosages. Generally, $\mathrm{Al}_{13}$ could achieve better removal than $\mathrm{PACl}$ within the whole experimental $\mathrm{pH}$ range regardless of the type of dyes, and the superiority of $\mathrm{Al}_{13}$ was more obvious under the lower dosage of $3 \times 10^{-5} \mathrm{moll}^{-1}$.

While in the case of $\mathrm{AlCl}_{3}$, its coagulation efficiency increased first and then tended to decrease rapidly with the decrease of $\mathrm{pH}$. The optimal $\mathrm{pH}$ range for $\mathrm{AlCl}_{3}$ varied with the type of dyes and level of dosages. Nevertheless, it can be deduced based on the overall results that the maximum removal occurred at $\mathrm{pH}$ around 6.0 for $\mathrm{AlCl}_{3}$, which was in agreement with the results reported by Lee et al. [3]. It can also be seen that under higher dosage, the coagulation zone of $\mathrm{AlCl}_{3}$ was broader than that under lower dosage. In addition, the coagulation zones corresponding to Direct Black 19 and Direct Red 28 were larger than that corresponding to Direct Blue 86.

Another feature shown in Fig. 7 is that even at the optimal $\mathrm{pH}$ for $\mathrm{AlCl}_{3}$, the coagulation efficiencies of both $\mathrm{PACl}$ and $\mathrm{Al}_{13}$ were higher than that of $\mathrm{AlCl}_{3}$ under most cases, particularly under the lower dosage of $3 \times 10^{-5} \mathrm{moll}^{-1}$.

In order to better understand the coagulation behaviors of three coagulants, the dye removal changes with the increase of dosage were investigated at both $\mathrm{pH}$ of 5.8 and 3.5 (Fig. 8). It is obvious that $\mathrm{Al}_{13}$ was the most efficient coagulant at both $\mathrm{pH}$ levels. PACl exhibited significantly higher removals than $\mathrm{AlCl}_{3}$ although the $\mathrm{pH}$ of 5.8 was within the coagulation zone favorable for $\mathrm{AlCl}_{3}$. It can be seen that the coagulation features of $\mathrm{AlCl}_{3}$ were markedly different under $\mathrm{pH}$ of 5.8 and 3.5. If the dosage was high enough, the dye removal by $\mathrm{AlCl}_{3}$ was able to reach near $100 \%$ at $\mathrm{pH} 5.8$. But under $\mathrm{pH}$ of 3.5, the coagulation efficiency of $\mathrm{AlCl}_{3}$ was dramatically deteriorated, and the dye removal could not achieve even $60 \%$ for all three dyes within the dosage range. Furthermore, in the coagulation of Direct Blue 86 , the removal curve approached a plateau value of only $50 \%$ removal. Meanwhile, no observable flocs developed for all the jar tests associated with $\mathrm{AlCl}_{3}$ at $\mathrm{pH}$ of 3.5. It has been reported that the $\mathrm{Al}$ species was dominated by $\mathrm{Al}_{\mathrm{a}}$ after dosing at $\mathrm{pH}$ of less than 4.0 when traditional $\mathrm{Al}$ salt was applied [21,24], thus it could be inferred that monomeric $\mathrm{Al}$ species was not effective for direct dye removal.

With the aid of dye removal measurement, careful observation of the floc developing process indicated that once appreciable flocs were formed, the dye removal could be reached relatively high levels of not less than $80 \%$. The $80 \%$ removal seemed to be a critical point for removing direct dyes by coagulation. In order to more clearly elucidate the effect of $\mathrm{pH}$ on the performance of different coagulants, the dosages required to achieve $80 \%$ dye removal for different coagulants were obtained by interpolating the corresponding curves of dosage versus removal under different $\mathrm{pH}$ conditions (Fig. 9). The dosages to achieve $80 \%$ removal decreased greatly with the reduction of $\mathrm{pH}$ for both $\mathrm{PACl}$ and $\mathrm{Al}_{13}$, and the associated dosages of $\mathrm{Al}_{13}$ were all lower than those of $\mathrm{PACl}$. From $\mathrm{pH} 7.80$ to 3.50, the dosages corresponding to $80 \%$ removal decreased more than $70 \%$ averagely for both $\mathrm{PACl}$ and $\mathrm{Al}_{13}$ despite the type of dyes.
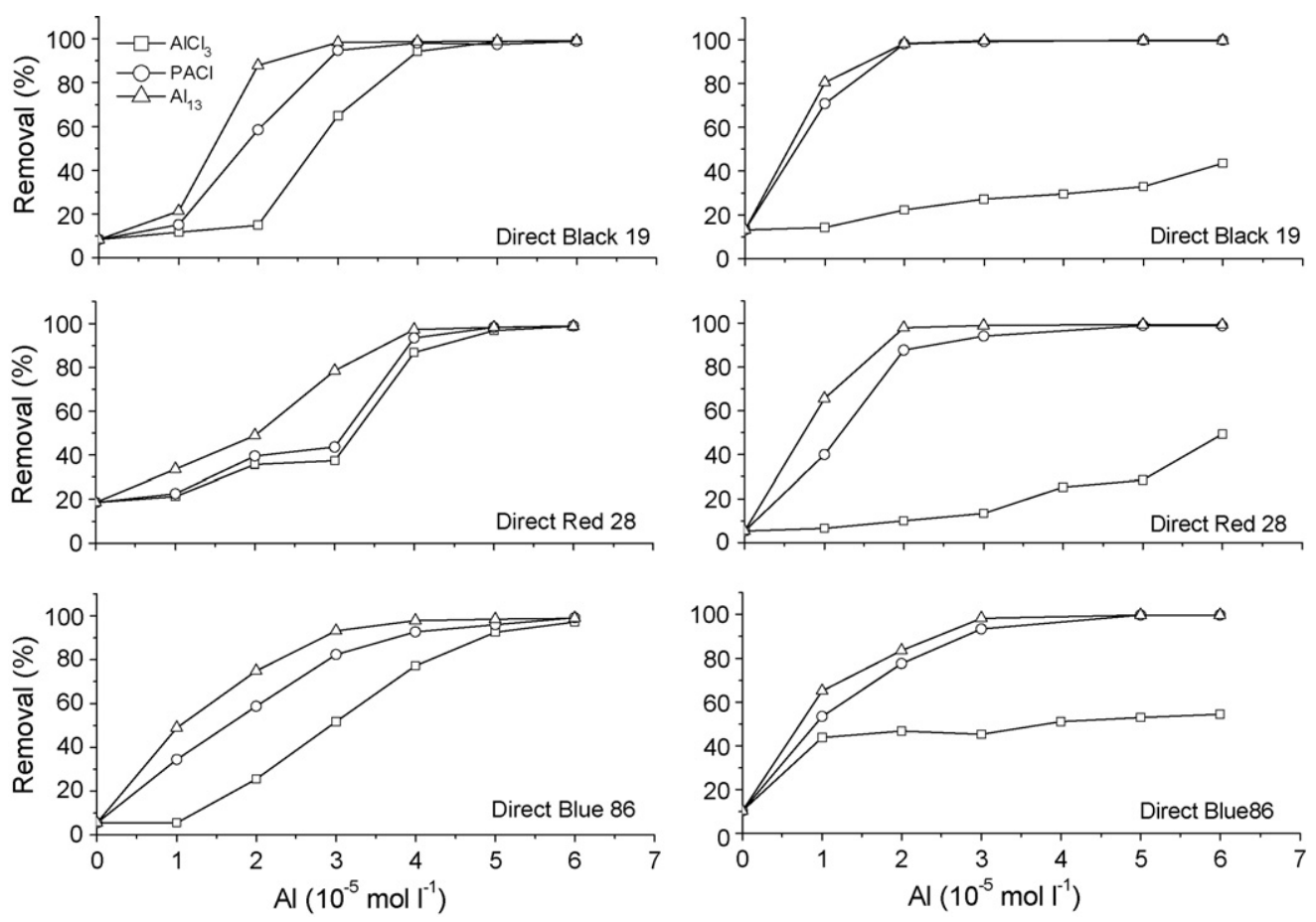

Fig. 8. Coagulation of direct dyes by $\mathrm{AlCl}_{3}, \mathrm{PACl}$ and $\mathrm{Al}_{13}$ at $\mathrm{pH}$ of 5.8 and 3.5 (left column: $\mathrm{pH} 5.8$; right column: $\mathrm{pH} 3.5$ ). 


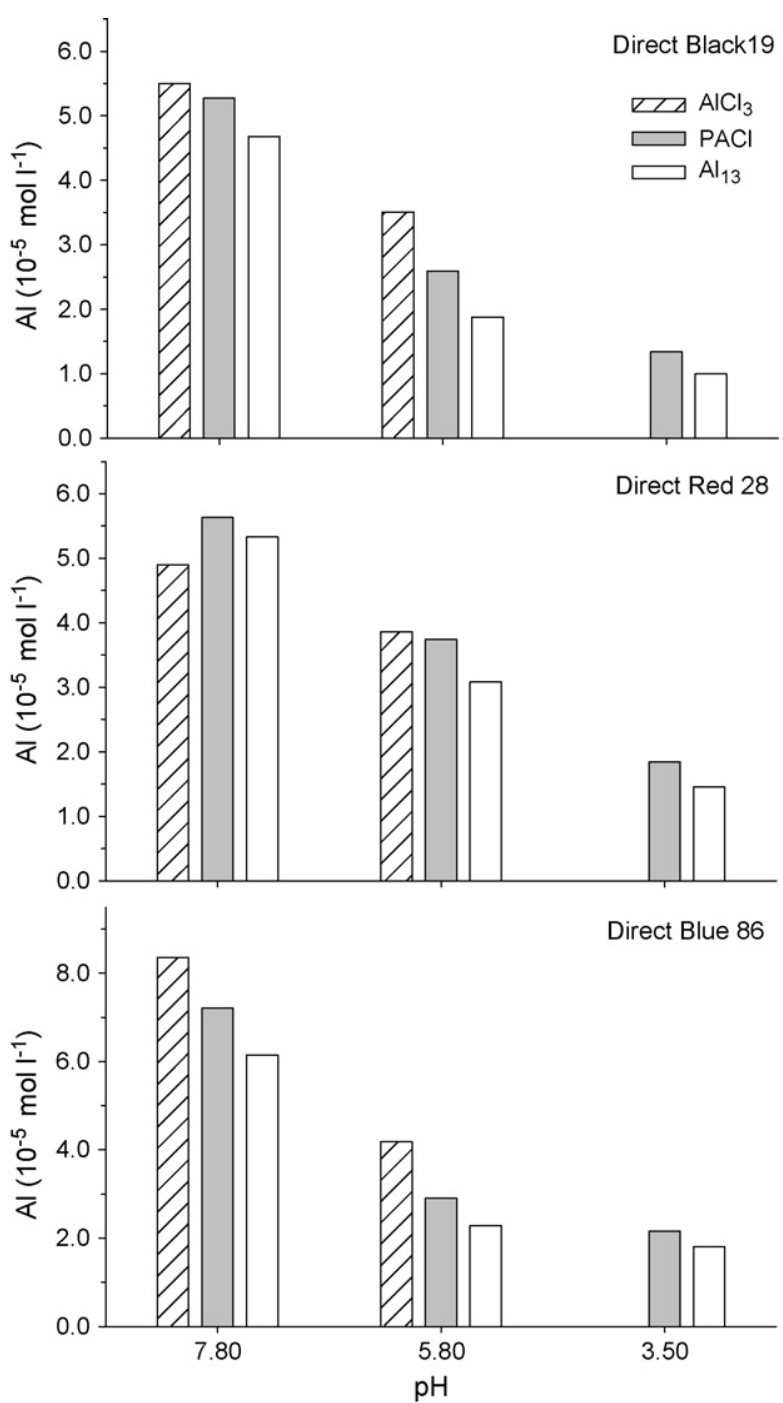

Fig. 9. Comparison of dosages required for achieving $80 \%$ dye removal at different $\mathrm{pH}$ conditions.

The required dosages of $\mathrm{AlCl}_{3}$ for $80 \%$ removal were lower at pH 5.8 than those at $\mathrm{pH} 7.80$, but $80 \%$ removal was not able to be reached at $\mathrm{pH} 3.5$.

As mentioned above, the type of dyes could affect the coagulation performance of different coagulants. To achieve $80 \%$ removal, Direct Blue 86 required higher dosage of $\mathrm{PACl}$ and $\mathrm{Al}_{13}$ than the other two dyes at $\mathrm{pH}$ of 7.80 and 3.50. However, at $\mathrm{pH}$ of 5.80, highest dosages of $\mathrm{PACl}$ and $\mathrm{Al}_{13}$ were needed for removal of Direct Red 28. When $\mathrm{AlCl}_{3}$ was applied, the highest dosage was with Direct Blue 86 at both $\mathrm{pH}$ of 7.80 and 5.80; while Direct Black 19 exhibited the poorest removal at pH of 3.50 (Fig. 8). Therefore, in order to achieve high treatment efficiency, the coagulation $\mathrm{pH}$ must be optimized based on the function of coagulants and the property of specific dyes at different $\mathrm{pH}$ conditions.

\subsection{Further discussion}

Many studies have confirmed that traditional coagulants and inorganic polymeric coagulants have much different coagulation behaviors and mechanisms [18-21,26]. Charge neutralization is considered to be a prerequisite condition for most coagulation processes to occur. In the case of traditional $\mathrm{Al}$ salts, charge neutralization is induced by the $\mathrm{Al}$ hydrolysis products formed in situ after dosing. The in situ formed Al hydrolysis products could aggregate, rearrange and further hydrolyze to amorphous hydroxide precipitate. Such freshly formed amorphous solids can further neutralize, adsorb colloidal matters and function as bridges among fine particles. At high dosages, the coagulation caused by amorphous hydroxide can be a dominant mechanism, which is the so-called "sweep flocculation". Previous work had demonstrated that $\mathrm{Al}_{\mathrm{a}}$ species could disappear rapidly and evolve into polymeric species in 2 min after dosing, and then further change to hydroxide precipitate gradually. However, preformed $\mathrm{Al}$ species, such as $\mathrm{Al}_{13}$ and colloidal species could possess relatively high stability after dosing in a broad $\mathrm{pH}$ range [24]. Therefore, it is difficult for them to form Al hydroxide by way of in situ hydrolysis. Due to the high positive charge (+7), $\mathrm{Al}_{13}$ has strong charge neutralization ability for negatively charged colloids or large molecules. In addition, $\mathrm{Al}_{13}$, with nanometer size, has tendency of self-assembly to form large aggregates, which makes it effective to function as bridges among particles. Thus, $\mathrm{Al}_{13}$ is considered to be the most efficient species for coagulation/flocculation by some researchers. As to the colloidal $\mathrm{Al}$ species $\left(\mathrm{Al}_{\mathrm{c}}\right.$ component), its charge neutralization ability is much less than that of $\mathrm{Al}_{13}$, although its stability is relatively high too. It has been observed that under some circumstances, the coagulation efficiency of colloidal $\mathrm{Al}$ species could be higher than that of $\mathrm{Al}_{13}$ species due to the larger size of such species. "Electrostatic patch coagulation" has been put forward to interpret the coagulation mechanism of colloidal $\mathrm{Al}$ species [19].

All the direct dyes used in this study contain sulfonic functional groups, which are negatively charged when dissolved in water. The electrostatic repulsion between negative charges on different molecules enhances the solubility of dyes. In order to coagulate these dyes, the negative charges of dye molecules need to be sufficiently neutralized. It could be one of the reasons that $\mathrm{Al}_{13}$, with high charge neutralization ability, is superior to the other coagulants in general. In the coagulation of Direct Red 28 under $\mathrm{pH}$ of tap water (Fig. 5), the higher removal by $\mathrm{AlCl}_{3}$ might be due to the "sweep flocculation" mechanism, which is inclined to occur at high dosage and high $\mathrm{pH}$ conditions.

On the other hand, with the decrease of $\mathrm{pH}$, dye protonation processes could lead to reduction of charge density and induce self-aggregation of dye molecules. Therefore, less coagulant would be required to destabilize them. As noted in Fig. 7, the coagulation of the dyes became much more easier with the decrease of $\mathrm{pH}$ (with the exception of $\mathrm{pH}$ less than 6.0 in the case of $\mathrm{AlCl}_{3}$ ). When $\mathrm{AlCl}_{3}$ was used as coagulant, the changing trend of dye removal with $\mathrm{pH}$ implied that the intermediate Al hydrolysis products (such as six-member ring $\mathrm{Al}$ species) could play an important role in dye coagulation process. When the $\mathrm{pH}$ was high (greater than 7.0), the $\mathrm{Al}$ hydrolysis could continue very rapidly and amorphous hydroxide would form in a short time. Thus, amorphous hydroxide was deemed to be the major product inducing the coagulation/flocculation. Due to the 
weaker charge neutralization ability, amorphous hydroxide was not effective in dye removal, particularly when the dosage was low. When the $\mathrm{pH}$ was in the low range (less than 5.0), the $\mathrm{Al}$ hydrolysis could be significantly inhibited, and the monomeric and/or oligomeric Al species would exist for a long duration, and these species was not as effective as polymeric $\mathrm{Al}$ species in terms of both charge neutralization and particle bridging functions.

\section{Conclusion}

Al based coagulants could be used to treat waters polluted by some direct dyes. The coagulation performances of traditional $\mathrm{Al}$ salt, $\mathrm{PACl}$ and purified $\mathrm{Al}_{13}$ were significantly different due to their different speciation characteristics. Preformed Al species, particularly $\mathrm{Al}_{13}$, could play important roles in the coagulation of direct dyes.

Adjustment of $\mathrm{pH}$ was necessary for improving dye removal efficiency and saving coagulant usage. For PACl and purified $\mathrm{Al}_{13}$, the decrease of $\mathrm{pH}$ was always beneficial for enhancing dye removal. With respect to traditional $\mathrm{Al}$ salt, an optimal $\mathrm{pH}$ of around 6.0 should be used.

Generally, purified $\mathrm{Al}_{13}$ had the highest dye removal efficiency. The importance of $\mathrm{Al}_{13}$ in coagulation of direct dyes could be attributed to its high charge neutralization ability, relative anti-hydrolysis stability and its nanometer-sized structure with self-assembly tendency.

\section{Acknowledgement}

This work was supported by the National Natural Science Foundation of China (Grant No. 20537020).

\section{References}

[1] T. Robinson, G. McMullan, R. Marchant, P. Nigam, Remediation of dyes in textile effluent: a critical review on current treatment technologies with a proposed alternative, Bioresour. Technol. 77 (2001) 247-255.

[2] S. Papić, N. Koprivanac, A.L. Božić, A. Meteš, Removal of some reactive dyes from synthetic wastewater by combined $\mathrm{Al}(\mathrm{III})$ coagulation/carbon adsorption process, Dyes Pigments 62 (2004) 291-298.

[3] J.W. Lee, S.P. Choi, R. Thiruvenkatachari, W.G. Shim, H. Moon, Evaluation of the performance of adsorption and coagulation processes for the maximum removal of reactive dyes, Dyes Pigments 69 (2006) 196-203.

[4] D.T. Sponza, M. Işık, Toxicity and intermediates of C.I. Direct Red 28 dye through sequential anaerobic/aerobic treatment, Process Biochem. 40 (2005) 2735-2744.

[5] I. Arslan, Treatability of a simulated disperse dye-bath by ferrous iron coagulation, ozonation, and ferrous iron-catalyzed ozonation, J. Hazard. Mater. B 85 (2001) 229-241.

[6] T.H. Kim, C. Park, J. Yang, S. Kim, Comparison of disperse and reactive dye removals by chemical coagulation and Fenton oxidation, J. Hazard. Mater. B 112 (2004) 95-103.
[7] U. Bali, E. Çatalkaya, F. Şengul, Photodegradation of Reactive Black 5, Direct Red 28 and Direct Yellow 12 using UV, UV/H2O2 and UV/H2O2/F22+: a comparative study, J. Hazard. Mater. B 114 (2004) 159-166.

[8] H. Selcuk, Decolorization and detoxification of textile wastewater by ozonation and coagulation processes, Dyes Pigments 64 (2005) 217-222.

[9] O.T. Can, M. Kobya, E. Demirbas, M. Bayramoglu, Treatment of the textile wastewater by combined electrocoagulation, Chemosphere 62 (2006) 181-187.

[10] H. Tamai, T. Yoshida, M. Sasaki, H. Yasuda, Dye adsorption on mesoporous activated carbon fiber obtained from pitch containing yttrium complex, Carbon 37 (1999) 983-989.

[11] J. Mo, J.E. Hwang, J. Jegal, J. Kim, Pretreatment of a dyeing wastewater using chemical coagulants, Dyes Pigments 72 (2007) 240-245.

[12] J.W. Lee, S.P. Choil, R. Thiruvenkatachari, W.G. Shim, Submerged microfiltration membrane coupled with alum coagulation/powdered activated carbon adsorption for complete decolorization of reactive dyes, Water Res. 40 (2006) 435-444.

[13] P.M. Bertsch, D.R. Parker, Aqueous polynuclear aluminum species, in: G. Sposito (Ed.), The Environmental Chemistry of Aluminum, 2nd ed., CRC Press Inc., 1996, pp. 117-168.

[14] Y.H. Shen, B.A. Dempsey, Synthesis and speciation of polyaluminum chloride for water treatment, Environ. Int. 24 (1998) 899-910.

[15] D. Wang, H. Tang, J. Gregory, Relative importance of charge neutralization and precipitation on coagulation of kaolin with PACl: effect of sulfate ion, Environ. Sci. Technol. 36 (2002) 1815-1820.

[16] K. McCurdy, K. Carlson, D. Gregory, Floc morphology and cyclic shearing recovery: comparison of alum and polyaluminum chloride coagulants, Water Res. 38 (2004) 486-494.

[17] C. Hu, H. Liu, J. Qu, D. Wang, J. Ru, Coagulation behavior of aluminum salts in eutrophic water: significance of $\mathrm{Al}_{13}$ species and $\mathrm{pH}$ control, Environ. Sci. Technol. 40 (2006) 325-331.

[18] C. Allegre, M. Maisseu, F. Charbit, P. Moulin, Coagulation-flocculationdecantation of dye house effluents: concentrated effluents, J. Hazard. Mater. B 116 (2004) 57-64.

[19] V. Golob, A. Vinder, M. Simonić, Efficiency of the coagulation/flocculation method for the treatment of dyebath effluents, Dyes Pigments 67 (2005) 93-97.

[20] T.H. Kim, C. Park, E.B. Shin, S. Kim, Decolorization of disperse and reactive dye solutions using ferric chloride, Desalination 161 (2004) 49-58.

[21] D.J. Joo, W.S. Shin, J.H. Choi, S.J. Choi, M.C. Kim, M.H. Han, T.W. Ha, Y.H. Kim, Decolorization of reactive dyes using inorganic coagulants and synthetic polymer, Dyes Pigments 73 (2007) 59-64.

[22] S.S. Liu, T.T. Liang, Return sludge employed in enhancement of color removal in the integrally industrial wastewater treatment plant, Water Res. 38 (2004) 103-110.

[23] B. Shi, G. Li, D. Wang, H. Tang, Separation of $\mathrm{Al}_{13}$ from polyaluminum chloride by sulfate precipitation and nitrate metathesis, Sep. Purif. Technol. 54 (2007) 88-95.

[24] D. Wang, W. Sun, Y. Xu, H. Tang, J. Gregory, Speciation stability of inorganic polymer flocculant-PACl, Colloid Surf. A-Physicochem. Eng. Aspects 243 (2004) 1-10.

[25] C. Feng, B. Shi, D. Wang, G. Li, H. Tang, Characteristics of simplified ferron colorimetric solution and its application in hydroxy-aluminum speciation, Colloid Surf. A-Physicochem. Eng. Aspects 287 (2006) 203-211.

[26] H.X. Tang, Z.K. Luan, The different coagulation behavior and mechanism between inorganic polymer flocculant and traditional coagulants, in: H.H. Hahn, E. Hoffmann, H. Ødegaard (Eds.), Chemical Water and Wastewater Treatment (IV), Springer-Verlag, Berlin, 1996, pp. 83-93. 